\title{
Applied Soft Computing on Virgin Olive Oil Elaboration Process Fuzzy Control of Grinding Stage
}

\author{
A. Jiménez Márquez \\ Instituto Andaluz de Investigación y Formación \\ Agraria, Pesquera, Alimentaria y de la Producción \\ Ecológica (IFAPA), Junta de Andalucía. \\ Centro 'Venta del Llano'. \\ PO. Box 50, E-23620 Mengibar, Jaén. Spain
}

\author{
G. Beltrán Maza \\ Instituto Andaluz de Investigación y Formación \\ Agraria, Pesquera, Alimentaria y de la \\ Producción Ecológica (IFAPA), Junta de Andalucía. \\ Centro 'Venta del Llano'. \\ PO. Box 50, E-23620 Mengibar, Jaén. Spain
}

\begin{abstract}
A decisional system on fuzzy logic based (DFS) was built for automatization of the olives fruit grinding stage, on extra virgin olive oils elaboration process, for modulation of 'biophenols' content (BPH) in the oils obtained. This Fuzzy model was integrated in a 'Simulink' laboratory simulator of this stage which consists on a PI feedback controller type. The input to controller was constituted by the fruits temperature, the pore size of sieve, the rotational speed of hammer mill and the error, which this is the difference between BPH levels predicted at simulator output versus the setpoint BPH level. The importance of these variable, on end level of BPH in oils, was established by 'data-mining' analysis which enabled defined the behavior rules and decisional tables for built the membership functions of Fuzzy system. The temperature, sieve and error were constituted the antecedent function for fuzzification and the hammer speed the consequent function for desfuzzification. A total of 27 rules 'if..the...and..then..' were extracted. To work with this laboratory simulator and verify the performance of the fuzzy model an EVOO process model an Artificial Neural Networks based (ANN) was used which was built by employing the Near Infrared (NIR) spectral properties of olives fruit and technological variables of process for prediction of BPH level in oils $\left(r=0.937\right.$, RMSE $\left.=354 \mathrm{mg} \mathrm{kg}^{-1}\right)$ at horizontal decanter output. This laboratory simulator was checked by application of different BPH setpoint step and monitorization of adjust of the BPH prediction to setpoint for the different hammer speeds established by de Fuzzy system, showing a good response in short times and the ability to modulate the $\mathrm{BPH}$ content within a wide range of these $\left( \pm 450 \mathrm{mg} \mathrm{kg}^{-1}\right)$ with respect to the initial value.
\end{abstract}

\section{General Terms}

Machine learning, Process Optimization, Intelligent Controls

\section{Keywords}

Fuzzy System, Data Mining, Artificial Neural Network, Soft computing, Artificial Intelligence, Olive Oil, Biophenols

\section{INTRODUCTION}

The production requirements that many current industrial processes are subjected: a better quality of the final product, decrease in production costs, greater work safety and maximum environmental respect, is causing an increase in the complexity of the systems to control. Nonlinear dynamics, time varying parameters and unpredictable circumstances, make the optimization of these be carried out under environments of great uncertainty.
The control of these processes usually exceeds the capabilities of classical control techniques, which perform the optimization of the systems with approximate mathematical models. Solution to this situation can been given with the application of intelligent control techniques which are capable of adsorbing these uncertainties, the lack of specificity in the objectives and the different restrictions to which are subject the process.

Data mining (DM), fuzzy logic systems (FS) and artificial neural networks (ANN), are some of the techniques that respond to this situation. Information extraction, decision making and control actions based on a training and learning process, based on the data collected of the process and the actions performed by an expert operator to execute the control, make the systems of Intelligent control can act autonomously, nonlinearly and adaptively, imitating the human actions [1].

These techniques are currently being widely used in many different areas of the control of industrial processes [2] [3] [4], in the cement plants [5], in the paper industry [6] [7], in the chemical industry [8], in the treatment plants [9] [10], and in the agri-food industries how in sugar [11], dryers [12] [13], dairy industries [14], fermentation industries [15], and the olive industry [16] [17].

In this last sector, the Virgin Olive Oil elaboration process (EVOO), is making an effort in its modernization with the incorporation of computerized systems and with a growing interest in the applicability of techniques, such as ANN, for the global optimization of the process [11] [18] [19] [20]. The process complexity, the lack of linearity between variables and their objectives, and the fact that the work instructions for these variables are still usually established in a subjective way from to the knowledge and experience of the 'oil mill master', make the EVOO process an ideal candidate for the implementation of intelligent control systems. More recently, fuzzy control techniques in the regulation of certain process automatisms [21] or 'datamining' techniques to obtain information on the behavior of different process variables [22] have been studied in order to achieve an improvement in the optimization of the EVOO process.

In this article, the feasibility of join application of these techniques for design control system of EVOO process were analysed from real data of process and by laboratory simulations, as preliminary step to an effective implementation in a real plant. As particular case, the work was focused one the essential stage: the grinding of the olives fruits and their effect on content of biophenols (BPH) in the processed oil. This treatment is very important due to the implication that these components have in the nutritional and sensorial characteristics of extra virgin olive oils (EVOO), whose the content on oils is 
affected by some process variables such as those studied in this paper.

\section{METODOLOGY}

\subsection{Equipment.}

This work was carried out using a continuous two phases system installed in "Venta del Llano" IFAPA Center [20].This system is constituted by a hammer crusher, a horizontal three bodies malaxer (500 $\mathrm{kg}$ each one), a horizontal centrifugal decanter (HCD) (nominal capacity of $45 \mathrm{t} /$ day) and a vertical centrifuge plate separator for oil cleaning. For the purpose of this work, the hammer crusher is constituted by a metal hammer cross whose rotation can be regulated externally by an electronic motor speed regulator, which allows working within the $1500-3000 \mathrm{rpm}$ range, and a production capacity of about $3250 \mathrm{~kg} \mathrm{~h}^{-1}$. This is equipped with a manually interchangeable metal sieve that rotates in the opposite direction to the rotation of the hammers, at a fixed speed. The sieve is made of stainless steel with perforations between $5-8 \mathrm{~mm}$. A ground olive mass with different particle size is obtained. Using a closed screw conveyor, the hammer crusher was fed with olives fruit at a constant flow of about $2500 \mathrm{~kg} \mathrm{~h}^{-1}$.

\subsection{Sampling, analysis methods and instrumentation.}

Along different years numerous tests were carried out by varying the most common conditions of EVOO process. Data on temperatures, flow rates, residence times, motor hertz, as well as product samples and spectral characteristics of these were taken. A total of 241 treatments were carried out, reduced to 185 after a filtering data and results. Olives fruit, oil samples at the output of the DCH and their spectral data were taken in triplicate on each treatment.

Total polyphenol content ( $\mathrm{mg} / \mathrm{kg}$ of caffeic acid) was determined as described by Vázquez-Roncero et al. (1973) [23].

NIR absorbance spectra of olives paste were obtained by an Acousto-Optic Tunable Filter (AOTF)-near infrared (NIR) (Brimrose Corp. EEUU) equipment through reflectance sensors. Spectra treatment, accord Jiménez et al. [20], convert the initial scanning, in range of $1100-2500 \mathrm{~nm}$, into spectra of only 39 points, for ANN model.

\subsection{Data mining.}

The free software Waikato Environment for Knowledge Analysis 3.6.9 (The University of Waikato Hamilton, New Zealand) was used. In this work classify techniques through 'decision trees classifier' was applied as described in previous paper [22].

\subsection{Fuzzy design.}

Toolbox 'fuzzy' from Matlab [24], to define inputs and outputs fuzzy sets, the membership functions and actuation rules, was used. For activation rules, triangular memberships (trimf), 'Mandani' method and minimum value, were applied. 'Centroid' method was used for output values defuzzification. The fuzzy model was exported to 'Simulink'.

\subsection{ANN-Virtual EVOO process.}

A supervised learning based Artificial Neural Network (ANN) model, from the algorithm descending gradients 'feed-forward back-propagation', was designed from software Matlab [24] as virtual EVOO process. Number of neurons per layer, the transfer functions between layers, the training algorithms and the number of iterations were tested, as described in Funnes et al. [25], for build a model which provided predictions to total Biophenols in olive oils from the DCH output.

\subsection{Grinding stage laboratory simulator.}

For grinding stage simulation a control scheme in Simulink environment from Matlab [24] was designed. This simulator contains the fuzzy model designed (DFS) and the ANN-model obtained and implemented by the 'gemsim' Matlab function.

\section{RESULTS}

\subsection{Data Mining for extract olives grinding stage information}

Data Mining to database of EVOO process collected on fourcrop years was applied [22]. These data have provide a wide range of values for biophenols content (BPH) in oils produced which were subdivided at five nominal classes from the practical and traditional experience on oil mill: Low (L), MidLow (ML), Mid (M), Mid-High (MH), High (H). The range for each class is show in Table 1.

Table 1. The nominal class and its associated range of BPH values from olive oils database used

\begin{tabular}{|c|c|}
\hline Nominal class & Ranges of BPH \\
\hline Low (L) & $<250 \mathrm{mg} \mathrm{kg}^{-1}$ \\
Mid.Low (ML) & $250 \mathrm{mg} \mathrm{kg}^{-1}<>500 \mathrm{mg} \mathrm{kg}^{-1}$ \\
Mid (M) & $500 \mathrm{mg} \mathrm{kg}^{-1}<>750 \mathrm{mg} \mathrm{kg}^{-1}$ \\
Mid-High (MH) & $750 \mathrm{mg} \mathrm{kg}^{-1}<>1000 \mathrm{mg} \mathrm{kg}^{-1}$ \\
High (H) & $>1000 \mathrm{mg} \mathrm{kg}^{-1}$ \\
\hline
\end{tabular}

The J48 algorithm application to training dataset and validation of them provides a prediction model that allows a high correct classification percentage upper to $81 \%$, as its can see in the confusion matrix showed in Table 2. The nominals class $\mathrm{L}$, ML, $\mathrm{M}$ and $\mathrm{H}$ showed the better classification percentage, the nominal class $\mathrm{MH}$ a lowest level due, possibly, to the few data that has fallen into this class. This means that the criteria used to build model are sufficient for explained the olive grinding effect in oil polyphenol content trough the stage variables: hammer mill speed (rpm), sieve diameter $(\mathrm{mm})$ and olives temperature $\left({ }^{\circ} \mathrm{C}\right)$.

Table 2. Confusion matrix for total biophenols content classification by $\mathrm{J48}$ algorithm

\begin{tabular}{|c|c|c|c|c|c|c|}
\hline $\begin{array}{c}\text { Classified } \\
\text { as: }\end{array}$ & Low & $\begin{array}{c}\text { Mid- } \\
\text { Low }\end{array}$ & Mid & $\begin{array}{c}\text { Mid- } \\
\text { High }\end{array}$ & High & $\begin{array}{c}\text { Class } \\
\text { percent }\end{array}$ \\
\hline Low & 130 & 7 & 1 & 0 & 3 & $92,90 \%$ \\
Mid-Low & 14 & 140 & 10 & 1 & 4 & $82,80 \%$ \\
Mid & 1 & 9 & 99 & 7 & 6 & $81,10 \%$ \\
Mid-High & 8 & 0 & 10 & 20 & 7 & $44,40 \%$ \\
High & 6 & 0 & 6 & 2 & 64 & $81,60 \%$ \\
\hline
\end{tabular}

In Table 3 the range values of these variables are show. From this prediction model, rpm was the most important variable and was subdivided into four ranges: less than 2300, between 23002550 , between $2550-2700$ and greater than 2700 . For ranges $<2300$ and $>2700$ was the sieve the next important variable and olive fruit temperature for the rest ranges. Likewise its can see that the BPH content has a different trend accord de hammer mill speed range. Thus, for $<2300 \mathrm{rpm}$ range tend to give mid 
to high values, for $2300-2500$ range mid to low values, in the $2550-2700$ range mid to high values if the olives temperature is under $11^{\circ} \mathrm{C}$ but mid to low values if this temperature is above them.

Table 3. Denomination and range of the variables studied for the grinding stage

\begin{tabular}{|c|c|c|}
\hline EVOO Plant Variables & $\begin{array}{c}\text { Denomi } \\
\text { nation }\end{array}$ & $\begin{array}{c}\text { Range of } \\
\text { values }\end{array}$ \\
\hline $\begin{array}{c}\text { Sieve pore diameter } \\
(\mathrm{mm})\end{array}$ & $\mathrm{Sd}$ & $5,6,7$ \\
$\begin{array}{c}\text { Hammer mill velocity } \\
(\mathrm{rpm})\end{array}$ & $\mathrm{Hms}$ & $2000-3000$ \\
$\begin{array}{c}\text { Olive fruit temperature } \\
\left({ }^{\circ} \mathrm{C}\right)\end{array}$ & $\mathrm{Oft}$ & $2.5-24$ \\
\hline
\end{tabular}

This datamining information has allowed the construction of a behavior table of these variables with respect to BPH levels, the detail of which can be seen in Table 4. In actual olive mills the olives temperature is very unwieldy, however the sieve diameter and hammer speed are easier to handle. The first by grind stop and change sieve, the second by real time changes, and non-stop, in the frequency of electrical motor of the mill. In this situation the olives temperature affects to hammer speed decision for a $\mathrm{BPH}$ content modulation, for a certain pore size of sieve. Thus, for example, for a small sieve $(5 \mathrm{~mm})$, if the olives are cold (Low), it would need to work at Medium-High / High rpm, in order to obtain Medium-High BPH levels. If the pore size of sieve is thick $(7 \mathrm{~mm})$, and the olives are hot, it would be necessary to work at very low $\mathrm{rpm}$ to obtain significant levels of $\mathrm{BPH}$, since otherwise, oils with lower contents would be obtained. Therefore the importance of regulation of the hammer mill speed is evident and the datamining information can allow constructed a decisional table about the handling of these variables.

Table 4. BPH levels obtained from the $\mathbf{j} 48$ classifier for the different combinations of the grinding stage variables: olive fruits temperature, hammer crusher speed and pore size sieve. (L, low. ML, midi-low. MH, midi-high. H, high)

\begin{tabular}{|c|c|c|c|c|c|}
\hline & \multirow{2}{*}{\multicolumn{2}{|c|}{$\begin{array}{c}\text { Hammer crusher } \\
\text { rpm }\end{array}$}} & \multicolumn{3}{|c|}{ Olive Fruits Temperature } \\
\hline & & & Low & Midi & High \\
\hline \multirow{12}{*}{ 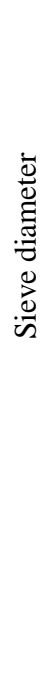 } & 5 & Low & ML & ML & $\mathrm{H}$ \\
\hline & & Midi-Low & ML & $\mathrm{L}$ & $\mathrm{H}$ \\
\hline & & Midi-High & MH & $\mathrm{L}$ & $\mathrm{L}$ \\
\hline & & High & M & ML & $\mathrm{H}$ \\
\hline & 6 & Low & ML & ML & $\mathrm{H}$ \\
\hline & & Midi-Low & ML & ML & MH \\
\hline & & Midi-High & $\mathrm{H}$ & $\mathrm{H}$ & $\mathrm{L}$ \\
\hline & & High & $\mathrm{H}$ & ML & $\mathrm{L}$ \\
\hline & 7 & Low & M & MH & $\mathrm{H}$ \\
\hline & & Midi-Low & ML & MH & ML \\
\hline & & Midi-High & MH & ML & ML \\
\hline & & High & $\mathrm{H}$ & ML & ML \\
\hline
\end{tabular}

\subsection{Decisional Fuzzy System (DFS) design.}

From datamining information a decisional fuzzy system (DFS) for help in making decision was build. Variables in the fruits grinding stage are clearly defined and can be segmented them into different categories to which words or linguistic labels can be assigned which will represent our perception of these variable in the diffuse universe. First, these variables were segmented in input and output accord to proportional type feedback control scheme on will be integrating (Figure 1).

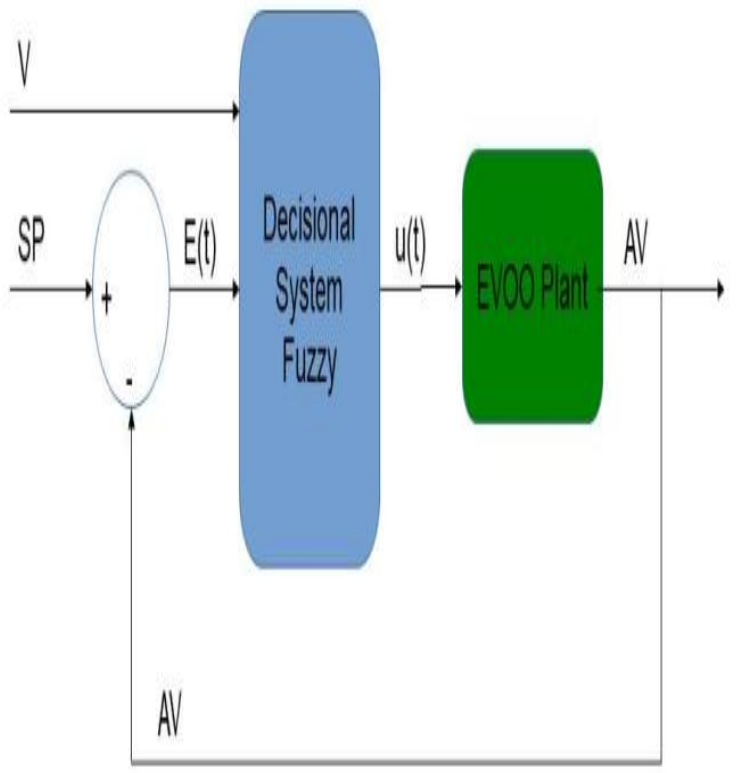

Figure 1. The scheme of a feedback control system with direct fuzzy controller. V: process variables. SP: BHP set point. $E(t)$ : error. $u(t)$ : fuzzy variable control. $A V$ : actual value of BPH

Pore diameter of sieve, olives temperature and error $\mathrm{E}(\mathrm{t})$ (as the difference between the set point marked as plant output target and the actual value of the parameter) were defined as input variables to DFS $(\mathrm{V})$, while the output vector $\mathrm{u}(\mathrm{t})$ was constituted by the 'rpm' regime that the mill must have to make the plant generate a level of BPH in the oil that makes zero the input error to the DFS E(t). Following the usual guidelines for the design of this type of fuzzy systems and once the input and output variables were established, the definition of the corresponding linguistic labels (fuzzification) associated with the ranks and membership functions are made from the decision tree generated by the datamining analysis previous.

On input vector three variables were considered. The olives temperature that was characterized by three fuzzy sets: Low $(\mathrm{L})$, Normal $(\mathrm{N})$ and High $(\mathrm{H})$. The pore size of sieve was defined by their three nominal values because intermediate values do not exist. The error $\mathrm{E}(\mathrm{t})$ was characterized by other three fuzzy sets: Negative (E-) when the BPH output is higher then the set point and an action on mill is necessary, Zero $(\mathrm{Z})$ when complies with the conditions of set point and non action is necessary, Positive (E+) when de BPH output is lower then the set point and also an action on mill is necessary.

On DFS output vector only the speed (rpm) of hammer mill was considered and three fuzzy sets were defined: rpm increase (I), rpm decrease (D) and non actuation $(\mathrm{N})$ with maintenance the current rpm regime. Table 5 show the labels, abbreviations and ranges defined for the memberships functions building. The initial memberships are shown in Figure 2. 
Table 5. Labels for input and output variables for design the decisional system fuzzy.

\begin{tabular}{|c|c|c|c|}
\hline $\begin{array}{c}\text { Var. } \\
\text { Type }\end{array}$ & Variable & $\begin{array}{c}\text { Label } \\
\text { (Abreviation) }\end{array}$ & Variable Range \\
\hline Input & $\begin{array}{c}\text { Olive fruit } \\
\text { temperature }\end{array}$ & $\begin{array}{c}\text { Low (L) } \\
\text { Normal (N) } \\
\end{array}$ & $\begin{array}{c}2.5-13,5^{\circ} \mathrm{C} \\
8-18,5^{\circ} \mathrm{C}\end{array}$ \\
& & High (H) & $13,5-24^{\circ} \mathrm{C}$ \\
\cline { 2 - 4 } & $\begin{array}{c}\text { Sieve } \\
\text { diammeter }\end{array}$ & $\mathrm{S} 5(\mathrm{~S} 5)$ & $5 \mathrm{~mm}$ \\
& $\mathrm{~S} 6(\mathrm{~S} 6)$ & $6 \mathrm{~mm}$ \\
& S7 (S7) & $7 \mathrm{~mm}$ \\
\cline { 2 - 4 } & Error & Positive (E+) & $0-1000 \mathrm{mg} \mathrm{kg}$ \\
& Zero (Z) & $-1000-1000 \mathrm{mg}^{-1}$ \\
& & Negative (E-) & $-1000-0 \mathrm{mg} \mathrm{kg}^{-1}$ \\
\hline
\end{tabular}

\begin{tabular}{|c|c|c|c|}
\hline Output & $\begin{array}{c}\text { Hammer } \\
\text { crusher } \\
\text { velocity }\end{array}$ & $\begin{array}{c}\text { Increase (I) } \\
\text { No actuation } \\
\text { (N) }\end{array}$ & $-600-600 \mathrm{rpm}$ \\
& & Decrease (D) & $-1000-0 \mathrm{rpm}$ \\
\hline
\end{tabular}

From Table 4 and Table 5 information a decisional table for the 'if...the...and..then...' rules were built. The input and the output variables were combined and 27 rules were extracted that they condense all possible control actions over the mill of the plant. These rules were synthesized as are shown on Table 6. From this decision table, it can see that, in general, to increase the $\mathrm{BPH}$ content the mill rpm regime must be increased, except when the olive temperature is high, in which case it is more convenient to reduce regime to avoid loss of BPH due to the effects of thermal degeneration.

'If sieve is 5 and the olive temperature is low and Error is $\mathrm{Z}$ no action on mill', would be an example of these rules.
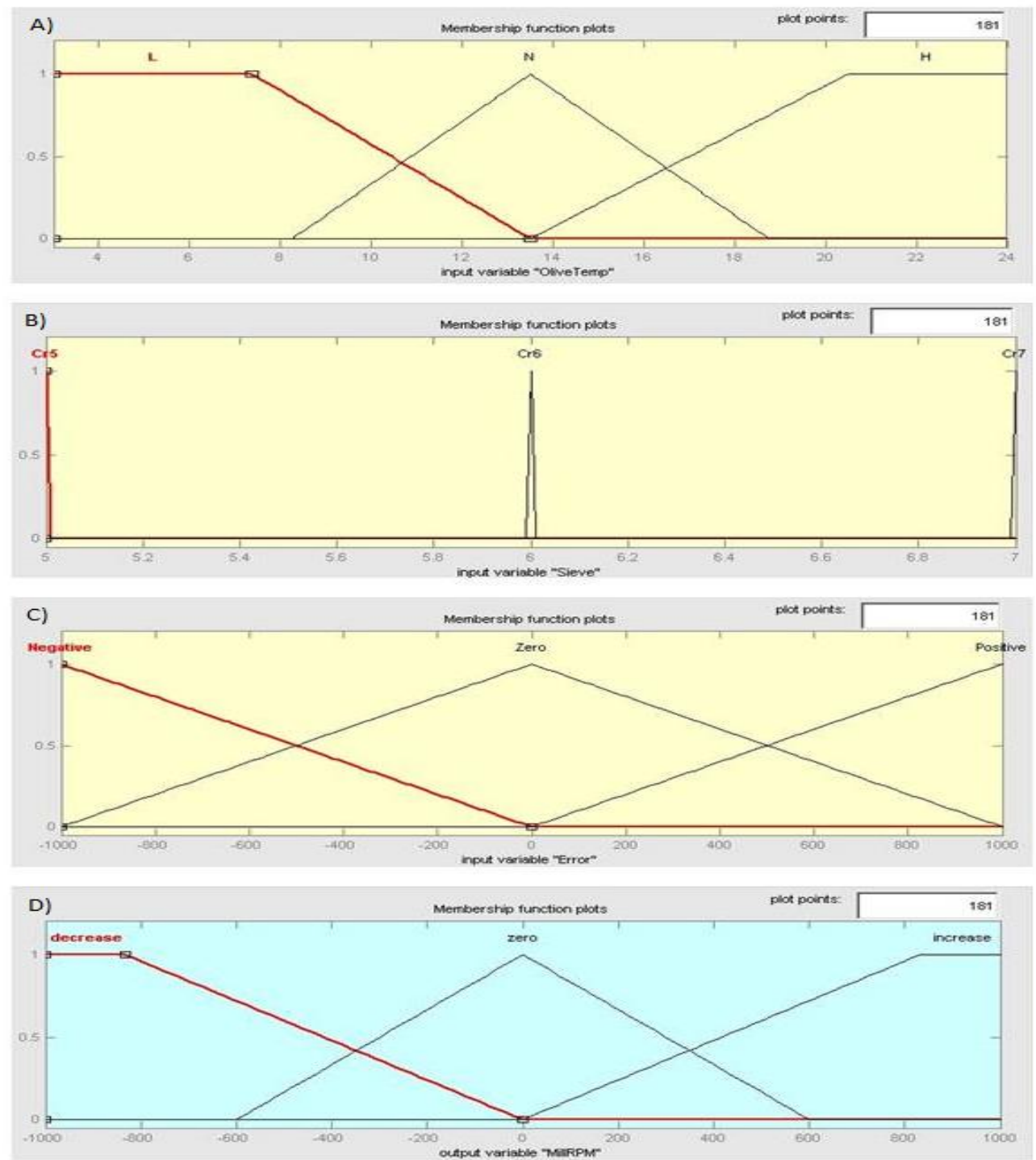

Figure 2. Membership functions for Fuzzy model. A) Olive fruits temperature. B) Size pore sieve. C) Error E(t). D) Hammer mill speed. ( From Matlab Fuzzy Logic Toolbox) 
Table 6. Decisional matrix for the fuzzy variable control. Actuation of the $u(t)$ on rpm of hammer crusher

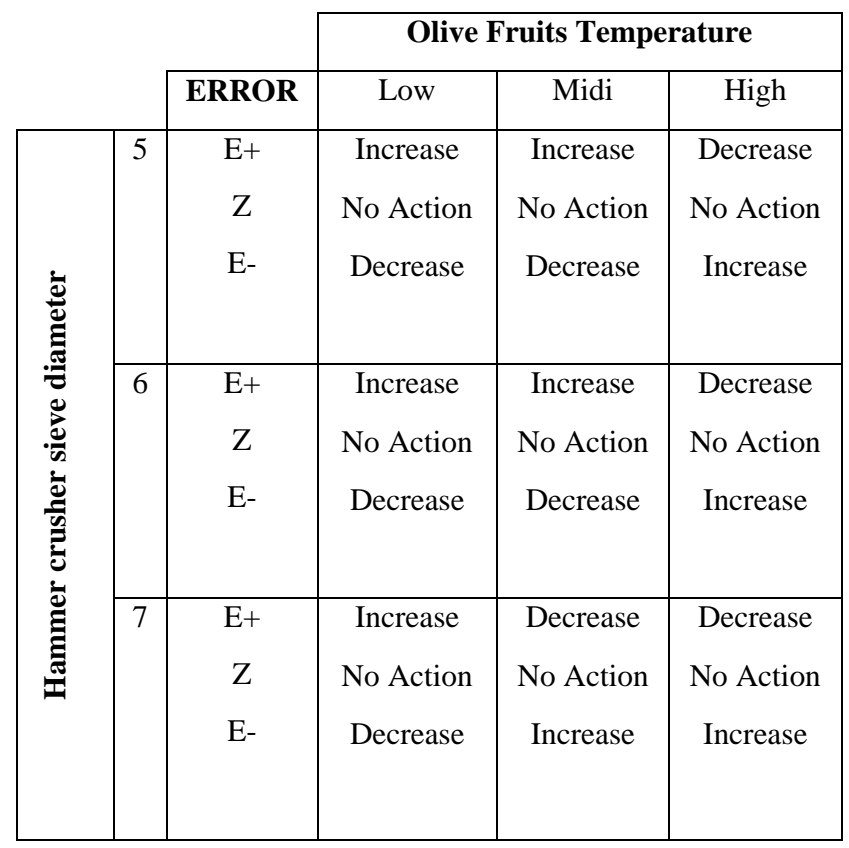

Designed the DFS, was incorporated into the feedback control scheme. The hammer mill speed, as control variable $\mathrm{u}(\mathrm{t})$, acts on EVOO process and, with the rest of its technological variables, a modulation of BPH level on oils is generated. This $\mathrm{BPH}$ level is compared with the set-point and the result is input to DFS along with the actual fruits temperature and sieve values.

\subsection{Fuzzy-ANN feedback controller and simulation}

To verify the correct performance of the DFS in the feedback controller on Figure 1, an EVOO plant model is necessary to perform simulations. In this sense, Artificial Neural Network was used to obtain the model and their build was made accord preliminary research to BPH content objective [10][20]. The EVOO-ANN model obtained was characterized by the topology showed in Table 7. The input vector 'p' was constituted by 10 EVOO technological variables and 39 discretized signal points of AOTF-NIR signal. The output vector ' $\mathrm{t}$ ' was assigned to quantitative level of BPH at output on DCH. This ANN model showed a good predictive capacity with a high coefficient of correlation $(\mathrm{r}=0.937)$ and acceptable predictive error $\left(\mathrm{RMSE}=354 \mathrm{mg} \mathrm{kg}^{-1}\right.$ ).

Table 7. ANN topology of EVOO model plant for BPH prediction

\begin{tabular}{|c|c|c|c|c|c|c|c|}
\cline { 3 - 7 } \multicolumn{2}{c|}{} & \multicolumn{4}{c|}{ ANN Training } & \multicolumn{2}{c|}{ ANN Validation } \\
\hline Parameter & NT/NV & $\begin{array}{c}\text { Layer_ } \\
\text { Neurons }\end{array}$ & $\begin{array}{c}\text { Transfer Layer } \\
\text { Functions }\end{array}$ & $\begin{array}{c}\text { ARN Training } \\
\text { Function }\end{array}$ & Iterations & $\mathrm{r}$ & RMSE \\
\hline $\begin{array}{c}\text { Total biophenols } \\
\left(\mathrm{mg} \mathrm{kg}^{-1}\right)\end{array}$ & $432 / 288$ & $75 / 46 / 1$ & Tsg/Tsg/Tsg & Trainrp & 300 & 0,937 & 354 \\
\hline
\end{tabular}

${ }^{1}$ NT, data numbers for training. NV, data numbers for validation.

Tsg, Sigmoid Transfer Function.

Trainrp, Resilient backpropagation Training Function.

RMSEP, Root Mean Squared Error Prediction.

The laboratory simulator of the feedback controller was designed from 'Simulink' (Matlab) using both DFS and ANN models. An overview of the process is shown in figure 3 . In this simulator a gain 'Gain' was introduced in order to tune the input of $\mathrm{E}(\mathrm{t})$ to DFS so that it allows a more uniform performance on the working range.

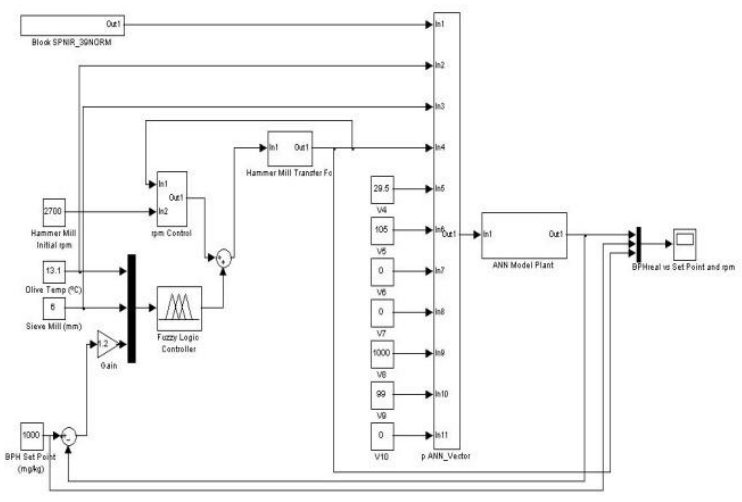

Figure 3. Schematic diagram of 'Simulink' laboratory simulator with the DFS and ANN models both included and for control of BPH content objective
Likewise, a transfer function for electrical motor of hammer mill 'hammer mill transfer Fc' was introduced because the rpm changes are not perform instantly. Also, a control block 'rpm control' , constituted by a 'block memory' and a 'block' switch', was included that allows to start the simulation of the plant with an initial rpm setpoint to pass, in the next simulation time, to the rpm established by the DFS. A multiplexor 'p_ANN-Vector' joins all variables to build the input vector ' $p$ ' to ANN. For simulation, data from a real test was applied. Discretized AOTF-NIR spectrum was used and loaded in the 'SPNIR_39NORM' block, the hammer mill variables and the 'Set Points' were established as the simulation start values, the rest of the EVOO process variables are established as constants. Different changes in the BPH content setpoint, as a step, were applied, which translate into a system response that tends to find the steady-state by modifying the rpm. As can be seen in Figure 4, a good performance of the fuzzy-ANN feedback control system is observed at the different requests to which it was subjected. In the first 100 units of time, the simulation starts with the experimental data from the real test, the hammer mill $\mathrm{rpm}$ increases until the $\mathrm{BPH}$ value predicted by the ANN equals the initial setpoint $\left(1000 \mathrm{mg} \mathrm{kg}^{-1}\right)$. This situation serves to evaluate the correct operation of the ANN model, the error was made zero and the value predicted obtained versus real value were the same. After the 
stabilization of the system, every 100 units of time, different BPH setpoint changes were applied. An adequate response of increasing or decreasing rpm was obtained until reaching the values that have allowed to ANN model predict the $\mathrm{BPH}$ content closest to the setpoint. In the next 100 units of time, for a setpoint change to $1300 \mathrm{mg} \mathrm{kg}^{-1}$, the DFS has resulted in a slight increase of rpm and an increase of BPH by EVOO model until reaching the new setpoint. For a decrease BHP setpoint since 1300 to $600 \mathrm{mg} \mathrm{kg}^{-1}$ a good adjustment to zero error was observed, but by under this level there are problems to adjust. A limit control situation was reached for the initial variables established to EVOO process and which are not enough to vary the mill rpm and achieve the objective, in this case a change on value of any of the crucial variable of mill would necessary. A decrease of pore size of sieve, from 6 to $5 \mathrm{~mm}$, solves the problem. By stabilizing the system again at $1000 \mathrm{mg} \mathrm{kg}^{-1}$, the application of a reduction step to $500 \mathrm{mg} \mathrm{kg}^{-1}$ no destabilize the system which responding appropriately. Under the conditions of this particular test and by means of the automatic regulation of the mill rpm regime, and occasionally the sieve manually, it is therefore possible to modulate the $\mathrm{BPH}$ content within a wide range of these $\left( \pm 450 \mathrm{mg} \mathrm{kg}^{-1}\right)$ with respect to the initial value

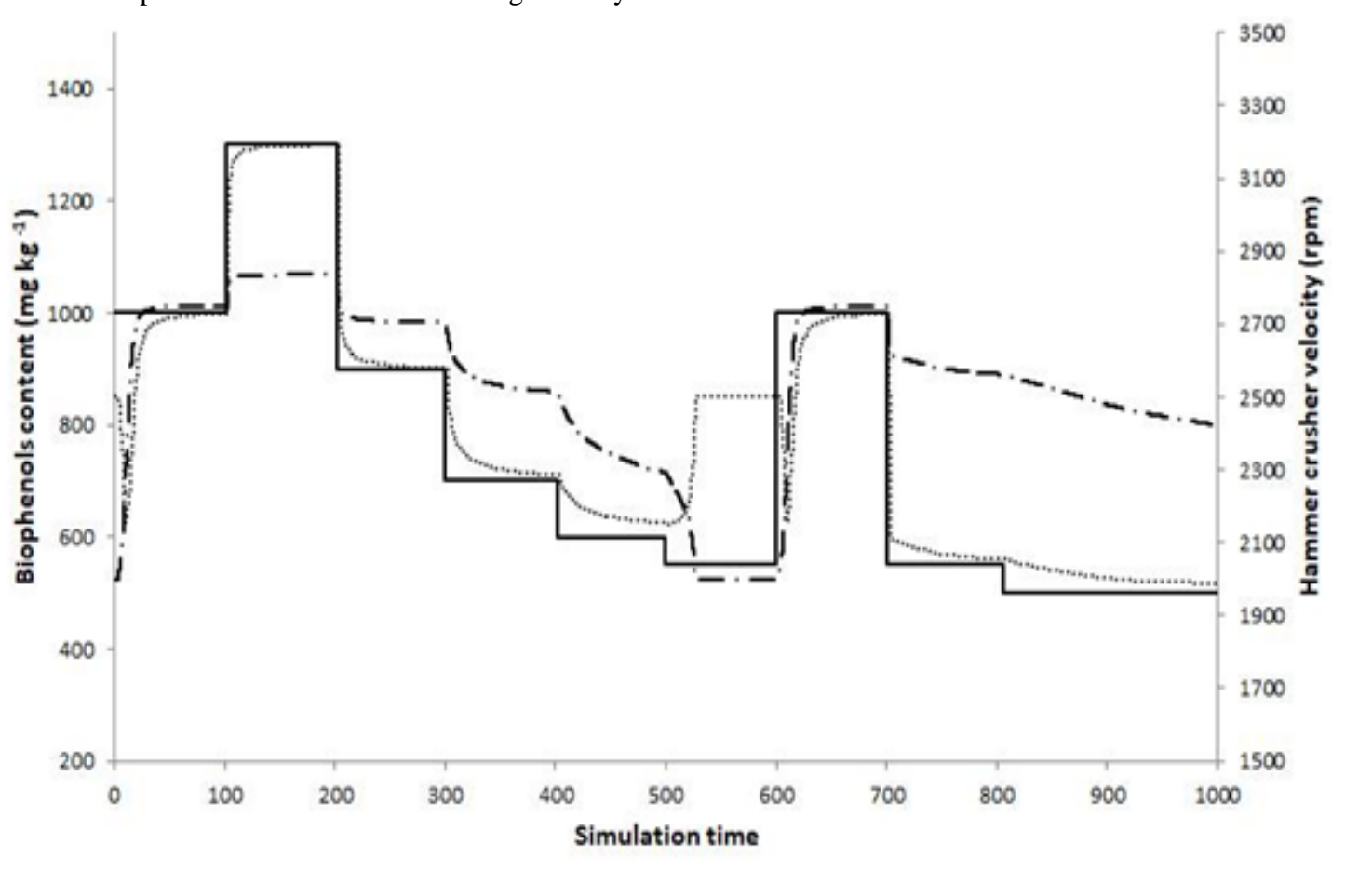

Figure 4: Simulation of automatic rpm hammer crusher regulation for different BPH set point applied. Initial condition on mill to 600 times: $\mathrm{S6}, \mathrm{rpm}=2700$ and $\mathrm{Oft}=13.5^{\circ} \mathrm{C}$; at 600 times sieve was changed to S5. BPH set point (------). BHP content predicted by ANN-Plant (..........). Values of fuzzy variable control for application to hammer crusher (-.-.-.-.-), in rpm

\section{CONCLUSIONS}

The combined use of modern process control techniques and historical real data, obtained during the EVOO process, can allow the development of intelligent controls for the different stages of the process.

Because of the specific features of this type of industry, which marked by the seasonality of its production, the design of these intelligent controllers has in laboratory simulators their first crucial stage, since they are the tools that allow verifying that will work correctly before being scaled to industrial level with a consequent saving of time, raw material and productive losses.

There are some essential elements for the correct operation of the simulators. The first, to have an extensive database that includes the physical-chemical characteristics of the olives fruits, olive oils and by-products, and the data on the different variables that manage the process, obtained from the different sensors and actuators installed. The second is necessary to have a reliable virtual model of the plant, built on the basis of the database, which allows visualizing rapid predictive responses to changes in the different variables to which it is subjected.

In this paper, the design of a Fuzzy controller for the initial stage of olive milling has required the use of data analysis using 'Data-Minig' to extract information about how the variables affect to this stage and build the membership functions and behaviour rules of controller, whose performance was optimized by applying it to a plant model based on artificial neural networks.

The results, shows the viability of the symbiosis between the different artificial intelligence techniques (Soft Computing) that working individually or in hybridization with other classical control techniques allow its real implementation on EVOO process and provide this industry to be favoured in its modern image, its efficiency and the improvement of the quality of its products.

\section{ACKNOWLEDGMENTS}

This work was supported by P10-AGR6429 Excellent Project: 'Modelling and Optimization of Virgin Olive Oil Elaboration Process. Project I', financed by 'Ministerio de Ciencia e Innovación' and 'Consejería de Economía, Innovación y Ciencia de la Junta de Andalucía' (Spain) and Proyect IFAPA.PPVA:AVA2016.12 'Virgin Olive Oil Quality and Safety. Objetiv 2: Intelligent Control in Virgin Olive Oil elaboration process', $80 \%$ financed by FEDER (FEDER Andalucía 2014-2020). Special thanks to Juan Torres and Justo 
Cardenas by their collaborations in oil mills and all the laboratory personnel.

\section{REFERENCES}

[1] Santos, M. 2011 An Applied Approach of Intelligent Control. Revista Iberoamericana de Automática e Informática Industrial, 8, 283-296.

[2] Magali, R., Meireles, G., Paulo, P., Almeida, M., Simäoes, M.G. 2003 A comprehensive review for industrial applicability of artificial neural networks. IEEE Transations on Industrial Elecronics, 50, 585-601.

[3] Funes, E., Allouche, Y., Beltrán, G., Jiménez, A. 2015 A Review: Artificial Neural Networks as Tool for Control Food Industry Process. Journal of Sensor Technology. 5, $28-43$

[4] Rebién, D.A., Maze, S.M., Havener, J.P. 1992 The application of neural networks in the process industry. Instrument. Soc. America, 31, 7-13.

[5] Negro, C., Alonso, A., Blanco, A., Tijero, J. 2006 Optimization of fiber cement composite process. Ind. Eng. Chem. Re,s 45, 197-205.

[6] Aguiar, H.E.; Maciel, A.; Maciel, R. 1998 Modeling and optimization of pulp and paper processes using neural networks. Computers Chem. Eng, 22, 981-S984.

[7] Edwards, P.J., Murray, A.F., Papadopoulos, G., Gordon, M.F., Wallace, A.R., Barnard, J., Smith, G. 1999 The applications of Neural Networks to the papermaking industry. IEEE Transactions on Neural Networks, 10, $1456-1464$.

[8] Farouq S. Mjalli, 2005 Neural network model based predictive control of liquid-liquid extraction contactors. Chemical Engineering Science, 60 (1), 239-253.

[9] Cristea V.M, Pop C., Agachi P.S. 2009 Artificial Neural Networks Modelling of PID and Model Predictive Controlled Waste Water Treatment Plant Based on the Benchmark Simulation Model No.1, In: Jacek Jeżowski and Jan Thullie, Editor(s), Computer Aided Chemical Engineering, Elsevier, 26, 1183-1188.

[10] Jaramillo, M. A., Peguero, J. C., Martínez de Salazar, E., García del Valle, M. 2001 Control Inteligente de una Estación Depuradora de Aguas Residuales mediante Redes Neuronales. XVII Congreso Nacional de Ingeniería de Proyectos. Murcia, Septiembre de 2001.

[11] Zamarreño J.M., Vega, P. 1997 Identification and predictive control of a melter unit used in the sugar industry. Artificial Intelligence in Engineering, 11 (4), 365-373.

[12] Ceylan, İ., Aktaş, I. 2008 Modeling of a hazenut dryer assisted heat pump by using artificial neural networks. Applied Energy, 85, 841-854.
[13] Mircea, V., Cristea, R.R., Şerban P. A. 2003 Neural networks based model predictive control of the drying process In: Andrzej Kraslawski and Ilkka Turunen, Editor(s), Computer Aided Chemical Engineering, Elsevier, 14, 389-394

[14] Khadir, M.T., Ringwood, J. 2001 Neural Network Modelling and Predictive Control of a Milk Pasteurisation Plant. In: Proceedings of the 7th International Conference on Engineering Applications of Neural Networks (EANN 2001), July 16-18 2001, Cagliari, Sardinia

[15] Steyer, J.P., Queinnec, I., Simoes, D. 1993 Biotech: a realtime application of artificial intelligence for fermentation processes. Control Eng. Practice, 1(2), 315-321.

[16] Izadifar, M., Zolghadri-Jahromi, M.2006 Application of genetic algorithm for optimization of vegetable oil hydrogenation process. Journal of Food Engineering, $78(1), 1-8$

[17] Marini, F., Magri, A.L, Bucci, R., Magri, A.D., Magri, A.L. 2007 Use of different artificial neural networks to resolve binary blends of monocultivar Italian olive oils. Analytica Chimica Acta, 599, 232-240.

[18] Furferi, R., Carfagni, M., Daou, M. 2007 Artificial Neural Network for real-time estimation of olive oil qualitative parameters during continuous extraction. Computers and electronics in agriculture, 55, 115-131.

[19] Jiménez, A., Beltrán, G., Aguilera, M.P., Uceda, M. 2008 A sensor-software based on artificial neural network for the optimization of the olive oil elaboration process. Sensor \& Actuator B, 129, 985-990.

[20] Jiménez A., Aguilera MP., Uceda M., Beltrán G. 2009 Neural network as tool for virgin olive oil elaboration process optimization. Journal of Food Engineering, 95(1), $135-141$.

[21] Jiménez, A. 2014 Aplicación de técnicas de control inteligente en almazaras. Diseño de un controlador borroso para la regulación e la adición de agua al 'Decanter Centrifugo Horizontal'. Editorial académica Española. ISBN :978-3-8484-5813-4.

[22] Jiménez A., Beltrán G. 2020 Data Mining for Rules Extraction to Virgin Olive Oil Optimization Process. International Journal of Computer Applications, 176(14)

[23] Vázquez Roncero, A., Janer Del Valle, C., Janer Del Valle, ML. 1973 Determinación de los polifenoles totales del aceite de oliva. Grasas y Aceites 24 (6), 350-357.

[24] Matlab 7.0, The MathWorks Inc., Natick, MA, USA.

[25] Funes,F, Allouche, Y., Beltrán, G., Aguilera, MP.,.Jiménez, A. 2017 A predictive artificial neural network model as a simulator of the extra virgin olive oil elaboration process. Journal of Near Infrared Spectroscopy. 